\title{
Vortex-induced vibrations of the Second Severn Crossing cable-stayed bridge: full-scale and wind tunnel measurements
}

\author{
J. H. G. Macdonald, P. A. Irwin and M. S. Fletcher
}

\section{J. S. Owen, University of Nottingham, UK}

I would first like to thank the authors for the extremely interesting paper that they have presented. There are some striking similarities between the large-amplitude behaviour that they have observed on the Second Severn Crossing and the behaviour that I, and others, recorded on the Kessock Bridge in Scotland. ${ }^{1-3}$ Large-amplitude response has been observed on both bridges under certain wind conditions. In both cases the large amplitude has been concentrated in the first mode of vibration. In both cases the response was sensitive to the wind regime, occurring for normal winds in a narrow range of velocities and with low levels of turbulence. In the light of these observations and the results of wind tunnel tests, both cases have been attributed to the vortex-shedding phenomenon. Although there are some differences in detail (for example SSC has a concrete deck whereas Kessock has an orthotropic stiffened plate), the overall structural form of the two bridges is similar-two deep-edge girders with cross-frames at regular intervals to provide torsional stiffness. The similarity of the bridges and the behaviour suggests that bridges of this form may be particularly susceptible to vortex-induced phenomena, and a more detailed comparison of the results from the two bridges may yield a better understanding of this behaviour and improved design recommendations.

However, in doing this it would be helpful to clarify the details of the mechanism involved. Having observed large-amplitude response on Kessock bridge and noted that it occurred principally in the first mode and corresponded to wind tunnel predictions of vortex-induced response, I, like the authors, have been quick to attribute this behaviour to vortex shedding. However, this conclusion has been questioned in some quarters. In particular it has been noted that the Kessock events occurred at a Reynolds number $\left(\operatorname{Re} \approx 4.3 \times 10^{6}\right)$ higher than that expected from classical bluff body aerodynamics and in a range where there is some doubt as to whether a stable vortex street can be established. For the SSC the value is similar $\left(\operatorname{Re} \approx 3.5 \times 10^{6}\right)$. Similarly, a rough back-calculation of Strouhal number for the two bridges (Kessock $S t \approx 0.07$ and SSC $S t \approx 0.05$ ) yields values that are, in each case, rather low. These observations suggest that the mechanism of aerodynamic loading is more complicated than the classic vortex-shedding phenomenon.
There has been some discussion in the literature about the part played by deck width in determining the overall response: partly by controlling whether vortices from the leading edge reattach, and partly in determining the phase relationship between vortices shed from the leading and trailing edges. The results presented in the paper are particularly interesting, as they seem to suggest that the mechanism will not involve separation and reattachment of vortices across the top of the deck (compare the presence of the windshields and also the success of modifying the aerodynamic form of the underside of the deck), and consequently it is vortex shedding from the lower flanges that drives the response. Do the authors have data from their wind tunnel tests that:

(a) confirm the presence of vortex shedding as the cause of the large-amplitude response, and, if so, indicate whether it is vortex shedding from the leading or trailing edges that drives the response?

(b) show how the baffles work to prevent large-amplitude response? Do the baffles break up vortices shed from the leading edge? Do the baffles disturb the flow, preventing vortices travelling across the underside of the deck? Do they interfere with vortices shed from the trailing edge?

It would be particularly interesting if the authors were able to publish flow visualisation data from the wind tunnel tests.

\section{Authors' reply}

The first point to make in response to John Owen's discussion is that the effect of Reynolds number on vortex shedding is, for practical purposes, negligible on very bluff cross-sections. Circular cylinders and other curved shapes do have a critical range of Reynolds number where transition of the surface boundary layers from laminar to turbulent (which is sensitive to Reynolds number) starts to occur early enough to enable the boundary layer to stay attached much further around the curved surface, thus delaying flow separation. The drag coefficient drops dramatically and the entire wake structure is altered, including some loss of correlation of the vortices in the wake in the critical Reynolds number range. However, it is well established that bluff structures with sharp edges force flow separation at the edges, regardless of Reynolds number.

There has been some evidence of Reynolds number 
dependence of the flow around certain bridge deck sections, including some variation of Strouhal number (up to 20\%). ${ }^{4,5}$ However, these tests have been on relatively streamlined box girders, for which reattachment of the boundary layer was possible in some conditions. For very bluff cross-sections such as the Second Severn Crossing (SSC) and Kessock bridges, reattachment is extremely unlikely. Wind tunnel measurements, at modest Reynolds number, of drag forces, and even such sensitive quantities as local pressure coefficients, have generally agreed very well with available full-scale data on sharp-edged bluff structures, even though the Reynolds number was two or three orders of magnitude higher at full scale. As shown in the paper, the measurements of vortex shedding behaviour of the SSC on the wind tunnel model agreed very well with the

full-scale observations, including agreement of the critical wind speed and hence Strouhal number. This tends to confirm the independence from Reynolds number.

There is no doubt in the authors' minds that what was seen on the SSC was vortex shedding, characterised by large-amplitude response in a single mode for a narrow critical range of wind velocity with low turbulence intensity. Concerning the source of the vortex excitation, it was found to be a function primarily of the flow on the underside of the deck. The underside cavity between the two edge girders was a place where a vortex could be seen, in flow visualisation tests with smoke in the wind tunnel, to be spinning up at roughly the $1 / 4$ chord position downwind of the leading girder. Once the vortex had grown to a certain intensity it would migrate downwind, negotiating its way around the trailing girder and passing off into the wake. Once the migration process was under way a new vortex would start to form at the $1 / 4$ chord point and the whole process would be repeated. Intuition indicated that a vertical baffle plate at the $1 / 4$ chord position, where the vortices were originating, would severely interfere with the vortex formation and thus may well have a favourable effect in reducing the excitation. The wind tunnel tests, and subsequently the full-scale measurements, confirmed this. It is worth noting that a number of devices were tried at or near the leading edge on the top side, but they were all ineffective, thus verifying that the flow over the top surface played a fairly insignificant role in the excitation.

The phenomenon of the underside vortices and the idea of baffle plates as a solution are not new. The second author encountered underside vortices in wind tunnel tests for a steel version of Dames Point bridge, Jacksonville, Florida, and baffle plates were developed as a solution in $1978 .{ }^{6}$ They were also proposed for a steel version of the Light Rapid Transit bridge in Vancouver in $1986 .{ }^{7}$ Underside vortices have been seen in wind tunnel tests on many other plate girder bridges since then, but they are not always strong enough to cause problems, and can be sensitive to the amount of turbulence in the oncoming wind.

The Strouhal numbers for the SSC and Kessock Bridge are indeed rather low compared with some other bridge decks-often it is around 0.1. However, values of 0.04-0.05 have been found by the second author to be typical for wide plate girder bridges, particularly when there are only two longitudinal girders. The deck width is indeed believed to be significant-from the point of view of girder spacing rather than of boundary layer reattachment. It is interesting to note that the Strouhal number calculated with respect to girder spacing, rather than the usual deck depth, is 0.45 for the SSC and approximately 0.5 for Kessock. These values are in quite close agreement and suggest that, for such cross-sections, the girder spacing may be the key dimension, rather than the deck depth. Although no further direct evidence of the detailed mechanism is available, this suggestion, and the flow visualisation observations above, are consistent with results from wind tunnel tests of wide rectangular prisms and $\mathrm{H}-$ sections, attributed to 'impinging leading edge vortices'., 89 These originate at the leading edge, but at a frequency inversely proportional to the distance to the trailing edge or downstream girder, owing to pressure feedback moving back upstream. They hence result in low Strouhal numbers, with respect to deck depth, for wide sections. The above values for the SSC and Kessock bridges also, interestingly, indicate that the spacing of vortices shed from the underside of the bridge is approximately twice the spacing between the girders.

\section{REFERENCES}

1. OWen J. S., Eccles B. J., Choo B. S. and Woodings M. A. The application of auto-regressive time series modelling for the time-frequency analysis of civil engineering structures. Engineering Structures, 2001, 23, No. 5, 521-536.

2. OWen J. S., VAnN A. M., Davis J. P. and Blakeborough A. The prototype testing of Kessock Bridge: response to vortex shedding. Journal of Wind Engineering and Industrial Aerodynamics, 1996, 60, 91-108.

3. Cullen-Wallace A. A. Wind influence on Kessock Bridge. Engineering Structures, 1985, 7, 18-34.

4. SCHEWE G. and LARSEN A. Reynolds number effects in the flow around a bluff bridge deck cross section. Journal of Wind Engineering and Industrial Aerodynamics, 1998, 74-76, 829-838.

5. Matsuda K., Cooper K. R., TANaka H., Tokushige M. and IWASAKI T. An investigation of Reynolds number effects on the steady and unsteady aerodynamic forces on a 1:10 scale bridge deck section model. Journal of Wind Engineering and Industrial Aerodynamics, 2001, 89, 619-632.

6. Irwin P. A., Savage, M. G. and WardlaW R. L. A Wind Tunnel Investigation of a Steel Design for the St Johns River Bridge, Jacksonville, Florida. National Research Council Canada, Ottawa, 1978, NAE Laboratory Technical Report LTR-LA-220.

7. IRWIN P. A. and Stone G. K. Aerodynamic improvements for plate girder bridges. Proceedings of the American Society of Civil Engineers Structures Congress, San Francisco, 1989, pp. $73-80$.

8. NAUDASCHER E. and WANG Y. Flow-induced vibrations of prismatic bodies and grids of prisms. Journal of Fluids and Structures, 1993, 7, 341-373.

9. NAKAMURA Y. and NAKASHIMA M. Vortex excitation of prisms with elongated rectangular, $\mathrm{H}$ and $\mathrm{T}$ cross-sections. Journal of Fluid Mechanics, 1986, 163, 149-169. 